\title{
PERIPHERAL MOTION CONTRAST SENSITIVITY AND OLDER DRIVERS' DETECTION FAILURE ACCIDENT RISK
}

\author{
Steven Henderson \\ Transportation Safety Board of Canada \\ Hull, Quebec, Canada \\ E-mail: Steve.Henderson@tsb.gc.ca
}

\author{
Don C. Donderi \\ McGill University \\ Montreal, Quebec, Canada
}

\begin{abstract}
Summary: Eighteen older drivers (66-88) and their passengers both reported on the drivers' performance using detection deficit questionnaires that elicited responses related to attention and to speed and accuracy of object motion perception. The measure of detection deficit was an equally weighted combination of standardized responses from the 17-item driver questionnaire and the 11-item passenger questionnaire. Peripheral stationary and drifting contrast sensitivity was determined for 0.4 cycles per degree sine wave gratings at fifteen degrees eccentricity. The temporal two-alternative forced choice staircase procedure consisted of randomly interleaved left and right visual field grating presentations. The correlation between $\log _{10}$ motion contrast sensitivity and detection deficit was $-.63(\mathrm{p}<.01)$, between age and detection deficit was $.56(\mathrm{p}<$ $.05)$, and between age and $\log _{10}$ motion contrast sensitivity was $-.54(\mathrm{p}<.05)$. The partial correlation between $\log _{10}$ motion sensitivity and detection deficit, independent of age, was $-.47(\mathrm{p}=.054)$. We concluded that some age-related driving performance deficits are associated with reduced sensitivity to motion in the visual periphery. Peripheral motion contrast sensitivity was discussed in relation to "useful field of view" $\left(\mathrm{UFOV}^{\circledR}\right)$ measures of visual function, and offered as a primary deficit of high risk drivers with mild Alzheimer's disease.
\end{abstract}

\section{INTRODUCTION}

Drivers more than sixty years of age are more likely than younger drivers to have fatal accidents, given equal mileage-estimated risk exposure (NHTSA, 2001; Yanik, 1986), and daytime fatality risk is higher for drivers over seventy-five than for any other age group (Massie, Campbell \& Williams, 1995). Physical frailty accounts for some of the fatality risk increase (Evans, Gerrish, \& Taheri, 1998; Li, Braver, \& Chen, 2003). However, older drivers are also more likely to be found at fault if they are involved in a multi-vehicle accident (Cooper, 1989; Stamatiadis \& Deacon, 1995), which may in part reflect a bias of accident investigators or police to attribute fault to older drivers.

Furthermore, mileage-based estimates of risk exposure can yield exaggerated accident risk estimates for older drivers (Janke, 1991). First, mileage estimates are usually based on selfreported data, which is likely to be inaccurate, and second, different driving environments expose drivers to widely differing levels of accident risk not captured in mileage-based estimates. 
A number of researchers have compared accident responsibility ratio (an induced exposure technique) across age groups to overcome the biases inherent in mileage-based accident rates. If a group has a ratio of at-fault accidents to not-at-fault accidents greater than one, then the group is involved in more than its expected share of two-vehicle accidents. Accident responsibility ratio increases at an accelerating rate after the age of sixty-five (Cooper, 1989, 1990; Janke, 1991; Stamatiadis \& Deacon, 1995; Verhaegen, Toebat, \& Delbeke, 1988). The proportion of right of way (ROW) violations to total traffic convictions by age also follows a similar rising curve (Cooper, 1990).

The age-related increases in both ROW violations and accident responsibility may result from failure to detect other vehicles in the right-of-way. Accident characteristics support this hypothesis. Young drivers' accidents are mostly single-vehicle crashes, while older drivers' accidents most frequently involve an undetected crossing vehicle at an intersection (Staplin, Gish, et al., 1998; Staplin, Lococo, et al., 1998; Viano, Culver, Evans, Frick, \& Scott, 1990). Furthermore, Summala and Mikkola (1994) found that only "failures of attention" (including detection) increase with age, among the five largest categories of primary non-alcohol causal factors for 1,357 fatal multi-vehicle accidents.

Some of the increase in driver accident responsibility with age may be caused by older drivers' reduced sensitivity to peripheral motion. In central vision, imparting motion enhances the contrast sensitivity of low spatial frequency sine wave gratings (below the CSF peak between 2 and 4 cycles/degree) by a factor of 4 or more. Motion enhancement (the ratio of drifting to stationary contrast sensitivity) begins to decrease after about 60 years of age, and may have fallen by a factor of 2 by the age of 70 (Owsley, Sekuler, \& Siemsen, 1983; Sekuler \& Owsley, 1982).

If motion sensitivity in the peripheral visual field follows a time course similar to motion sensitivity in central vision, then some of the characteristic failure of detection accidents of older drivers may arise from a peripheral motion processing (PMP) deficit that reduces the power of a moving stimulus to attract visual attention (Steinman, Steinman, Trick, \& Lehmkuhle, 1994) and to produce a reflexive saccadic eye movement toward it (Fuchs, Kaneko, \& Scudder, 1985; Stein, 1984). According to this hypothesis, a PMP deficit reduces the salience of a moving object, thus disrupting the preattentive stage of scan-path generation and serial search.

We carried out a correlational test of the hypothesis that self and peer-reported detection deficit in older drivers is related to a PMP deficit that reduces the ability of a moving stimulus to trigger reflexive visual attention. In other words, a measured decrease in PMP will increase reports of detection deficit among susceptible older drivers. Because groups of older drivers are highly variable on both vision measures and driving performance measures, if there is such a correlation between a vision measure (PMP in this case) and driving performance, it will be strongest among older drivers (Shinar \& Schieber, 1991). Another advantage of studying older drivers is that they have relatively few accidents involving alcohol (NHTSA, 2004). 


\section{METHOD}

\section{Participants}

Eighteen licensed and active drivers $(66-88, M=74.3, S D=5.6)$ and their passengers filled out respective driving performance questionnaires. All participants were unpaid volunteers recruited from senior citizen's services or church groups.

\section{Procedure}

Motion processing measure. Pilot testing of gratings presented at 15 degrees nominal eccentricity found motion enhancement ratios (MERs) of 3 to 4 for 0.4 cycles per degree gratings, comparable to central vision MERs for gratings of 1 cycles per degree (Sekuler \& Owsley, 1982), while MERs were usually less than 2 for 0.8 cycles per degree gratings presented at that eccentricity.

Accordingly, contrast sensitivity was determined for 0.4 cycles per degree stationary and drifting sine wave gratings. Moving gratings were drifted centripetally at a rate of 13.75 degrees per second $(5.5 \mathrm{hz})$, which is the optimal motion enhancement velocity (i.e., the temporal contrast sensitivity peak) for that spatial frequency (Kelly, 1979, 1984), given eccentricity scaling. Gratings generated by a purpose-built display driver (Cushman, 1992) were presented on two display monitors $57 \mathrm{~cm}$ distant from the head fixation point. The monitors had $10.2 \mathrm{~cm}$ wide by $8.2 \mathrm{~cm}$ high nongridded rectangular oscilloscope screens (P31 fast phosphor, $.038 \mathrm{msec}$ decay constant), spanning 10 degrees to 20 degrees of visual eccentricity on either side of an eye-level red LED fixation point.

A temporal two-alternative forced choice (t2afc) staircase method was used. A single stimulus consisted of a vertical sine-wave grating presented in a raised cosine temporal window of 1.5 seconds duration, preceded and followed by a 0.5 second blank interval. During a trial, the participant looked directly ahead at the lit LED fixation point, and indicated whether a grating stimulus appeared in the first or the second 2.5 second temporal interval (i.e., "before or after the double beep" separating the intervals). A trial was discarded before evaluation if the participant made an anticipatory eye movement.

Left and right visual field staircases were randomly interleaved. Within a staircase, the grating contrast increased after an incorrect response, and decreased after five successive correct responses, oscillating about the contrast yielding $89 \%$ correct responses (i.e., where $\mathrm{p}^{\mathbf{5}}=5(1-\mathrm{p})$ ).

The participant was blind to temporal interval and grating location, and the experimenter was blind to temporal interval. A trial block continued for at least 20 trials within each staircase after four contrast reversals within each staircase, and the threshold measure for each block was the mean grating contrast of the final 20 or more trials. The stationary grating block always preceded the moving grating block. A block usually took 40 minutes to 1 hour.

Initial grating contrast was determined by the method of ascending limits. For six randomly ordered (by side) test trials, the participant looked at the central red LED, and responded "left" or "right" as soon as a grating of gradually increasing contrast appeared on either the left or right 
oscilloscope screen. Then, t2afc training trials with high-contrast stimuli were conducted until $100 \%$ response accuracy was achieved for eight trials (usually within the first eight trials).

Driving performance measures. Driving performance was assessed by a two-part (driver and passenger responses) driving perception questionnaire designed to elicit information about the subjective effects of reduced detection distances and/or an increased probability of detection errors. The passenger, selected by the driver, sealed the completed passenger questionnaire into a supplied envelope before returning it to the driver, who brought both the driver's and passenger's completed questionnaires to the vision test session.

The 17 driver questions related to perceptions of traffic speed, their own driving speed relative to several standards, self-ratings of own driving performance relative to several standards, and selfreport of how often they were surprised by a range of driving events. The 11 passenger questions asked for judgements of average speed of the driver relative to city and highway traffic, the driver's relative performance and safety, how often the passenger detected various situations before the driver, and the passenger's overall state of mind. The 28 questions were combined by orienting the responses so that higher values reflected higher hypothetical risk (i.e., detection deficit), converting responses for each question to z-scores across drivers, and then computing the average $\mathrm{z}$-score for each driver. This procedure is equivalent to assigning equal weights in a regression equation, involves no capitalization on chance, and is unaffected by missing answers (Wainer, 1976).

\section{Experimental hypothesis}

Within a group of older drivers, peripheral motion contrast sensitivity would correlate significantly $(\mathrm{p}<.05)$ with detection deficit as assessed by questionnaire scores.

\section{RESULTS}

Table 1. Pearson Product Correlations between Age, Contrast Sensitivity, and Questionnaire Scores $(N=18)$

\begin{tabular}{lcccc}
\hline & Age & $\begin{array}{c}\text { Questionnaire } \\
\text { scores }\end{array}$ & $\begin{array}{c}\text { Driver } \\
\text { questionnaire }\end{array}$ & $\begin{array}{c}\text { Passenger } \\
\text { questionnaire }\end{array}$ \\
\hline Age & - & $.56^{*}$ & $.50^{*}$ & .43 \\
$\log _{10}$ contrast sensitivity (drifting) & & & & \\
$\quad$ Right visual field & $-.70^{* *}$ & $-.55^{*}$ & $-.53^{*}$ & -.39 \\
$\quad$ Left visual field & -.37 & $-.64^{* *}$ & $-.64^{* *}$ & -.42 \\
$\quad$ Average across fields & $-.54^{*}$ & $-.63^{* *}$ & $-.62^{* *}$ & -.43 \\
Log $_{10}$ contrast sensitivity (stationary) & & & & \\
$\quad$ Right visual field & -.34 & -.04 & -.08 & .01 \\
$\quad$ Left visual field & -.29 & -.25 & -.34 & -.07 \\
Average across fields & -.35 & -.18 & -.26 & -.04 \\
\hline
\end{tabular}

$* p<.05 . * * p<.01$. 
Mean $\log _{10}$ contrast sensitivity was $1.68(S D=0.17)$ for stationary 0.4 cycles per degree sine wave grating stimuli, and $2.15(S D=0.18)$ for drifting grating stimuli. Correlations of interest are shown in Table 1. The partial correlation between motion sensitivity and detection deficit questionnaire score, independent of age, was -.47 $(p=.054)$. As well, driver and passenger questionnaire scores just failed to correlate significantly with each other $(r=.41, p<.1)$.

\section{DISCUSSION}

Test and remediation. Note particularly that the correlation between peripheral motion processing and questionnaire score is stronger than their correlations with age, indicating that peripheral motion contrast sensitivity may therefore be used to identify drivers at higher risk for detection failure accidents without regard for age, fulfilling the requirement that such tests not be age-based.

Although older drivers do compensate for age-related visual and driving deficits (Slzyk, Seiple, \&Viana, 1995), they are poor at assessing their own visual processing skills and at detecting gradual visual losses occurring over time. They are unlikely to recognise the situations, intersections in particular, that are most dangerous for them (Holland, 1993). However, when informed of specific visual deficits by an eye care practitioner, older drivers willingly adopt compensatory strategies. Peripheral motion processing tests could be used to identify the deficit, and perhaps at-risk drivers could be taught to consciously scan the visual field at regular intervals and when approaching intersections, rather than having to rely on a reduced or absent reflexive orienting response to movement. (Note that flight instructors spend significant time instructing their students to consciously scan the visual field outside the aircraft.) Indeed, Scheiber (1994) stated that research should be conducted to determine if drivers with peripheral vision deficits might benefit from training in eye movement strategies.

Useful field of view. Ball, Owsley, and co-workers have proposed that a primary deficit causing driving performance decline is an age-related reduction in useful field of view (UFOV $\left.{ }^{\circledR}\right)($ Ball \& Owsley, 1991; Ball, Owsley, Sloane, Roenker, \& Bruni, 1993; Ball \& Rebok, 1994; Owsley, Ball, \& Keeton, 1995; Owsley, Ball, Sloane, Roenker, \& Bruni, 1991). UFOV ${ }^{\circledR}$ test participants perform simultaneous peripheral target localisation and central target discrimination. Stimulus duration is shorter than saccade latency, preventing serial search of the visual field. Visual Attention Analyser results can significantly predict prior accident involvement.

Ball, Owsley, and co-workers have suggested that pure sensory measures do not improve the fit of the regression model over $\mathrm{UFOV}^{\circledR}$ measures alone because they do not capture the complexity of the cluttered driving environment. Clinical ophthalmology tests (most particularly contrast sensitivity) typically isolate measurements of sensory function from perceptual and cognitive influences, assess only central vision, do not require concurrent use of central and peripheral vision, and incorporate no positional or temporal uncertainty in the test stimulus (Ball \& Owsley, 1991; Ball et al., 1993; Owsley et al., 1991). However, the sensory measure of peripheral motion processing described above does minimise perceptual and cognitive influences, while using peripheral vision during central fixation, and incorporating both positional and temporal uncertainty into the test stimulus.

The PMP test and the UFOV ${ }^{\circledR}$ test are complimentary measures of the visual attention required 
to drive safely. The (sensory) PMP test evaluates the power of motion to produce a saccade target (i.e., bottom-up scan-path generation), and the (attentional) $\mathrm{UFOV}^{\circledR}$ test evaluates the extent of information available for visual search within a fixation. PMP and UFOV ${ }^{\mathbb{R}}$ measures are not entirely independent, as the second sub-test of the UFOV ${ }^{\circledR}$ test requires peripheral localisation of a solitary step-onset stimulus, a task that probably overlaps with motion detection under spatial uncertainty.

Scialfa, Thomas, and Joffe (1994) found that age-related shrinkage of UFOV increases the serial component of search tasks (parallel to serial compensation). Older participants increased visual search reaction time by requiring more saccades to identify search targets. Therefore, a relatively more sensitive PMP system and more accurate saccade generator will help compensate for UFOV shrinkage (due to age or stroke) and mitigate its impact on driving performance. Conversely, a large UFOV likely reduces the need for accurate saccades. Therefore, including the PMP test in a test battery could reduce false positives by "deselecting" drivers better able to compensate for a UFOV deficit, thereby improving identification of high-risk drivers.

Alzheimer's disease, peripheral motion sensitivity, and accident risk. Estimates of increased crash risk for drivers with Alzheimer's disease (AD) compared to age-matched controls range from a factor of 5 (Friedland et al., 1988), to a factor of 2.5 (Tuokko, Tallman, Beattie, Cooper, \& Weir, 1995). Although researchers have considered the elevated accident risk of AD patients to be a function of cognitive impairment (Fitten et al., 1995; Kraszniak, Keyl, \& Albert, 1991; Parasuraman \& Nestor, 1991; Tuokko et al., 1995), crashing and non-crashing AD drivers are not distinguishable by neuropsychological tests or by symptom severity at initial diagnosis (Lucas-Blaustein, Filipp, Dungan, \& Tune, 1988; Tuokko et al., 1995). We contend for the following reasons that PMP deficit causes elevated accident risk in some AD drivers.

Visual deficits are now recognised by clinical researchers as a primary deficit of AD (CroninGolomb, 1995). One clinical subgroup of early AD patients displays Balint's syndrome (a visuospatial and motion processing deficit) as the first symptom of AD (Hof et al., 1993). Motion detection pathways, including middle temporal cortex, appear to be "dramatically affected in these cases" (p. 215). Some mildly demented early AD patients show profound visual deficits for temporally modulated stimuli. Detection thresholds are higher for drifting or flickering sine wave gratings (Gilmore, Wenk, Naylor, \& Koss, 1994; Hutton, Morris, Elias, \& Poston, 1993) and for $700 \mathrm{msec}$ presentations of step-onset gratings (Cronin-Golomb et al., 1991; Nissen et al., 1985) relative to healthy age-matched controls.

Some researchers have shown that correlated motion thresholds for random dot stimuli are more than double for AD patients (Gilmore et al., 1994; Silverman, Tran, Zimmerman, \& Feldon, 1994; Trick \& Silverman., 1991). However, Mendola, Cronin-Golomb, Corkin, and Growdon $(1992,1995)$ found no threshold increase using the correlated motion paradigm, perhaps because their stimuli could evoke correct "blindsight" responses from AD patients. This is made more plausible because Silverman et al. (1994) detected optokinetic nystagmus (OKN) for undetected random-dot motion, demonstrating relative sparing of accessory optic system processing in AD relative to cortical dysfunction. Increased visual evoked potential (VEP) latencies of P2 (indicating defective secondary visual processing), and temporal contrast sensitivity losses have also been reported (Wright, Drasdo, \& Harding, 1987).

If a sensory visual attention deficit is the cause of elevated crash risk in some early AD patients, then a variant of the PMP test (perhaps modified into a spatial two-alternative task to eliminate 
any memory demand) may reliably distinguish between crashing and non-crashing AD drivers. If so, diagnosis of probable early Alzheimer's disease need not mean termination of a patient's right to drive, as early $\mathrm{AD}$ drivers with low risk of sensory attention deficit could continue to drive until precluded by later AD deficits.

Future steps. The validity and reliability of peripheral motion processing measures and the driving perception questionnaire for predicting accident risk should be tested using accident data and driving simulator performance measures. We hope that further development of the forcedchoice method and test equipment will reduce test time sufficiently to make peripheral motion processing assessment practical for driving examiners, medical professionals, and transportation researchers.

By means such as these, we hope that personal mobility commensurate with functional vision may be preserved by mitigating functional deficits through appropriate training interventions, by restricting licenses when necessary, and perhaps eventually by developing effective visual prostheses or other technological countermeasures for visual function deficits not yet recognized.

Note: This research was conducted at McGill University in partial fulfillment of the doctoral thesis requirement of the first author. Please note also that road safety is outside the mandate of the Transportation Safety Board of Canada.

\section{REFERENCES}

Ball, K., \& Owsley, C. (1991). Identifying correlates of accident involvement for the older driver. Human Factors, 33(5), 583-595.

Ball, K., Owsley, C., Sloane, M. E., Roenker, D. L., \& Bruni, J. R. (1993). Visual attention problems as a predictor of vehicle crashes in older drivers. Investigative Ophthalmology \& Visual Science, 34(11), 3110-3123.

Ball, K., \& Rebok, G. (1994). Evaluating the driving ability of older adults. The Journal of Applied Gerontology, 13(1), 20-38.

Cooper, P. J. (1989). Differences in accident characteristics among elderly drivers and between elderly and middle-aged drivers. Proceedings of the 33rd Conference of the American Association for Automotive Medicine, 33, 153-167.

Cooper, P. J. (1990). Different ages, different risks: The realm of accident statistics. In J. P. Rothe (Ed.), The Safety of Elderly Drivers: Yesterday's Young in Today's Traffic, 85-133. New Brunswick: Transaction Publishers.

Cronim-Golomb, A. (1995). Vision in Alzheimer's disease. The Gerontologist, 35(3), 370-376.

Cronin-Golomb, A., Corkin, S., Rizzo, J. F., Cohen, J., Growdon, J. H., \& Banks, K. S. (1991). Visual dysfunction in Alzheimer's disease: relation to normal aging. Annals of Neurology, 29, 41-52.

Cushman, W. B. (1992). A low-cost spatial contrast sensitivity display driver. Behavior Research Methods, Instruments, \& Computers, 24(3), 461-463.

Evans, L., Gerrish, P. H., \& Taheri, B. (1998). Epidemiology of the older driver - some preliminary findings from data through 1996. Proceedings of the 16th International 
Conference on the Enhanced Safety of Vehicles, Windsor, Canada, 1-4 June 1998.

Fitten, L. J., Perryman, K. M., Wilkinson, C. J., Little, R. J., Burns, M. M., Pachana, N., Mervis, J. R., Malmgren, R., Siembieda, D. W., \& Ganzell, S. (1995). Alzheimer and vascular dementias and driving: a prospective road and laboratory study. Journal of the American Medical Association, 273(17), 1360-1365.

Friedland, R. P., Koss, E., Kumar, A., Gaine, S., Metzler, D., Haxby, J. V., \& Moore, A. (1988). Motor vehicle crashes in dementia of the Alzheimer type. Annals of Neurology, 24, 782-786.

Fuchs, A. F., Kaneko, C. R. S., \& Scudder, C. A. (1985). Brainstem control of saccadic eye movements. Annual Review of Neuroscience, 8, 307-337.

Gilmore, G. C., Wenk, H. E., Naylor, L. A., \& Koss, E. (1994). Motion perception and Alzheimer's disease. Journal of Gerontology: Psychological Sciences, 49(2), 52-57.

Hof, P. R., Archin, N., Osmand, A. P., Dougherty, J. H., Wells, C., Bouras, C., \& Morrison, J. H. (1993). Posterior cortical atrophy in Alzheimer's disease: analysis of a new case and reevaluation of a historical report. Acta Neuropathologica, 86(3), 215-223.

Holland, C. A. (1993). Self-bias in older drivers' judgements of accident likelihood. Accident Analysis and Prevention, 25(4), 431-441.

Hutton, J. T., Morris, J. L., Elias, J. W., \& Poston, J. N. (1993). Contrast sensitivity dysfunction in Alzheimer's disease. Neurology, 43, 2328-2330.

Janke, M. K. (1991). Accidents, mileage and the exaggeration of risk. Accident Analysis \& Prevention, 23(2/3), 183-188.

Kelly, D. H. (1979). Motion and vision. II. Stabilized spatio-temporal threshold surface. Journal of the Optical Society of America, 69, 1340-1349.

Kelly, D. H. (1984). Retinal inhomogeneity. I. Spatiotemporal contrast sensitivity. Journal of the Optical Society of America, A, 1(1), 107-113.

Kraszniak, A.W., Keyl. P. M., \& Albert, M. S. (1991). Dementia and the older driver. Human Factors, 33(5), 527-537.

Li G., Braver E. R., Chen L. H. (2003). Fragility versus excessive crash involvement as determinants of high death rates per vehicle-mile of travel among older drivers. Accident Analysis and Prevention, 35(2), 227-235.

Lucas-Blaustein, M. J., Filipp, L., Dungan, C., \& Tune, L. (1988). Driving in patients with dementia. Journal of the American Geriatrics Society, 36, 1087-1091.

Massie, D. L., Campbell, K. L., \& Williams, A. F. (1995). Traffic accident involvement rates by driver age and gender. Accident Analysis and Prevention, 27(1), 73-87.

Mendola, J. D., Cronin-Golomb, A., Corkin, S., \& Growdon, J. H. (1992). Vision in Alzheimer's disease: prevalence of deficit. Society for Neuroscience Abstracts, 18, 736.

Mendola, J. D., Cronin-Golomb, A., Corkin, S., \& Growdon, J. H. (1995). Prevalence of visual deficits in Alzheimer's disease. Optometry and Vision Science, 72, 155-167.

National Highway Traffic Safety Administration (2001). Traffic Safety Facts 2000: Older Population. DOT HS 809328. 
National Highway Traffic Safety Administration (2004). Traffic Safety Facts 2003: Older Population. DOT HS 809766.

Nissen. M. J., Corkin, S., Buonanno, F. S., Growdon, J. H., Wray, S. H., \& Bauer, J. (1985). Spatial vision in Alzheimer's disease: general findings and a case report. Archives of Neurology, 42, 667-671.

Owsley, C., Ball, K., \& Keeton D. M. (1995). Relationship between visual sensitivity and target localization in older adults. Vision Research, 35(4), 579-587.

Owsley, C., Ball, K., Sloane, M. E., Roenker, D. L., \& Bruni, J. R. (1991). Visual/cognitive correlates of vehicle accidents in older drivers. Psychology and Aging, 6(3), 403-415.

Owsley, C., Sekuler, R., \& Siemsen, D. (1983). Contrast sensitivity throughout adulthood. Vision Research, 23(7), 689- 699.

Parasuraman, R., \& Nestor, P.G. (1991). Attention and driving skills in aging and Alzheimer's disease. Human Factors, 33(5), 539-557.

Schieber, F. (1994). Recent developments in vision, ageing and driving 1988-1994. Report No. UMTRI-94-26. Ann Arbor, MI: University of Michigan, Transportation Research Institute. Viewed April 20, 2005 at: http://www usd edu/ schieber/pdf/umtri pdf on.

Scialfa, C. T., Thomas, D. M., \& Joffe, K. M. (1994). Age differences in the useful field of view: an eye movement analysis. Optometry and Vision Science, 71(12), 736-742.

Sekuler, R., \& Owsley, C. (1982). The spatial vision of older humans. In R. Sekuler, D. Kline, \& K. Dismukes (Eds.), Aging and Human Visual Function (pp. 185-202). New York: Alan R. Liss, Inc.

Shinar, D. \& Schieber, F. (1991). Visual requirements for safety and mobility of older drivers. Human Factors, 33(5), 507-519.

Silverman, S. E., Tran, D. B., Zimmerman, K. M., \& Feldon, S.E. (1994). Dissociation between the detection and perception of motion in Alzheimer's disease. Neurology, 44, 1814-1818.

Stamatiadis, N. \& Deacon, J. A. (1995). Trends in highway safety: Effects of an aging population on accident propensity. Accident Analysis and Prevention, 27(4), 443-459.

Staplin, L., Gish, K. W., Decina, L. E., Lococo, K., \& McKnight, A. S. (1998). Intersection Negotiation Problems of Older Drivers, Volume I: Final Technical Report. USDOT/NHTSA Contract No. DTNH22-93-C-05237. Washington, DC.

Staplin, L., Lococo, K., McKnight, A. J., McKnight, A. S., \& Odenheimer, G. (1998). Intersection Negotiation Problems of Older Drivers, Volume II: Background Synthesis on Age and Intersection Driving Difficulties. USDOT/NHTSA Contract no. DTNH22-93-C05237. Washington, DC.

Stein, B. E. (1984). Development of the superior colliculus. Annual Review of Neuroscience, 7 , 95-125.

Steinman, S. B., Steinman, B. A., Trick, G. L., \& Lehmkuhle, S. (1994). A sensory explanation for visual attention deficits in the elderly. Optometry and Vision Science, 71(12), 743-749.

Summala, H., \& Mikkola, T. (1994). Fatal accidents among car and truck drivers: Effects of fatigue, age, and alcohol consumption. Human Factors, 36(2), 315-326. 
Szlyk, J. P., Seiple, W., \& Viana, M. (1995). Relative effects of age and compromised vision on driving performance. Human Factors, 37(2), 430-436.

Trick, G. L., \& Silverman, S. E. (1991). Visual sensitivity to motion: Age-related changes and deficits in senile dementia of the Alzheimer type. Neurology, 41, 1437-1440.

Tuokko, H., Tallman, K., Beattie, B. L., Cooper, P., \& Weir, J. (1995). An examination of driving records in a dementia clinic. Journal of Gerontology: Social Sciences, 50B(3), S173S181.

Verhaegen, P. K., Toebat, K. L., \& Delbeke, L. L. (1988). Safety of older drivers: A study of their overinvolvement ratio. Proceedings of the 32nd Conference of the Human Factors Society, 185-188.

Viano, D. C., Culver. C. C., Evans, L., Frick, M., \& Scott, R. (1990). Involvement of older drivers in multi-vehicle side impact crashes. Accident Analysis \& Prevention, 22(2), 177-188.

Wainer, H. (1976). Estimating coefficients in linear models: It don't make no nevermind.

Psychological Bulletin, 83(2), 213-217.

Wright, C. E., Drasdo, N., \& Harding, G. F. A. (1987). Pathology of the optic nerve and visual association areas: information given by the flash and pattern visual evoked potential, and the temporal and spatial contrast sensitivity function. Brain, 110, 107-120.

Yanik, A. J. (1986). What accident data reveal about elderly drivers. (SAE Technical Paper \#851688). Warrendale, PA: Society of Automotive Engineers. 